\title{
Recurrent prognostic factors and expression of GLUT-1, PI3K and p-Akt in adenoid cystic carcinomas of the head and neck: Clinicopathological features and biomarkers of adenoid cystic carcinoma
}

\author{
JIN FANG $^{1,2}$, YANG-YANG BAO ${ }^{1}$, SHUI-HONG ZHOU ${ }^{1}$, XING-MEI LUO ${ }^{1}$, \\ HONG-TIAN YAO ${ }^{3}$, JIAN-FENG $\mathrm{HE}^{4}$ and QIN-YING WANG ${ }^{1}$ \\ ${ }^{1}$ Department of Otolaryngology, The Second Hospital of Jiaxing City, Jiaxing 314000; \\ Departments of ${ }^{2}$ Otolaryngology, ${ }^{3}$ Pathology and ${ }^{4}$ Oral and Maxillofacial Surgery, The First Affiliated Hospital, \\ College of Medicine, Zhejiang University, Hangzhou, Zhejiang 310003, P.R. China
}

Received April 5, 2012; Accepted July 18, 2012

DOI: $10.3892 / \mathrm{ol} .2012 .895$

\begin{abstract}
The purpose of this study was to explore the factors associated with the recurrence of adenoid cystic carcinomas (ACCs). We examined the recurrence values of clinicopathological variables and GLUT-1, p-Akt and PI3K expression in 42 patients with ACC. Of the 42 patients, 17 developed recurrence following initial surgery. The positive rates of GLUT-1, PI3K and p-Akt protein expression in ACC were 38.1, 38.1 and $50.0 \%$, respectively. The expression of GLUT-1, p-Akt or PI3K protein in ACC was higher than that in inflammatory lesions or benign tumors. Our study demonstrated that $\mathrm{T}$ stage, a positive resection margin, perineural invasion, surgery without postoperative radiotherapy and the expression of GLUT-1, PI3K and $\mathrm{p}$-Akt were factors predictive of recurrence by univariate analyses. In multivariate analyses, perineural invasion, a positive resection margin and p-Akt were significant predictors of recurrence. Initial surgery is very significant in the recurrence of ACC. Overexpression of GLUT-1, PI3K and p-Akt may also play a role in its development and recurrence.
\end{abstract}

\section{Introduction}

Adenoid cystic carcinoma (ACC) in the minor salivary glands, including the larynx, nasal cavity, paranasal sinus, external auditory canal and trachea, is uncommon (1-4). ACC is noted for its slow growth and indolent course and, as with ACC in the

Correspondence to: Professor Shui-Hong Zhou, Department of Otolaryngology, The First Affiliated Hospital, College of Medicine, Zhejiang University, 79 Qingchun Road, Hangzhou, Zhejiang 310003, P.R. China

E-mail: zhouyunzhoush@163.com

Key words: adenoid cystic carcinomas, recurrence, immunohistochemistry, glucose transporter-1, PI3K/Akt pathway major salivary glands, patients with ACC of these sites often experience recurrence and distant metastases many years after diagnosis and definitive treatment (5). The patterns of disease include perineural and vascular invasion. The most significant modalities for the primary treatment of local and locoregional disease are surgery and/or irradiation. However, the long-term outcome of these treatments is unfavorable (6). Several studies have identified clinicopathological factors in ACC with an unfavorable effect on survival, including old age, tumor location, advanced stage, solid histological subtype, high grade, tumor-node-metastasis (TNM) staging, major nerve involvement, the presence of perineural invasion, a positive surgical margin and lymph node metastasis $(7,8)$. However, the real prognostic and recurrence factors are still unknown. Thus, further studies are needed to identify the pathogenesis, prognostic factors and new diagnostic and therapeutic methods for ACC, particularly at the molecular level.

Like other malignant tumors, ACC cells exhibit increased glucose uptake and utilization compared with their nonmalignant counterparts. This phenomenon has been demonstrated by positron emission tomography (PET) using ${ }^{18} \mathrm{~F}$-2-fluoro-2-deoxy-D-glucose ( $\left.{ }^{18} \mathrm{~F}-\mathrm{FDG}\right)$ (9). Many mechanisms of ${ }^{18} \mathrm{~F}-\mathrm{FDG}$ uptake have been proposed for accelerated glucose use in growing tumors and in transformed and malignant cells. These include passive diffusion, $\mathrm{Na}^{+}$-dependent glucose transport and facilitative glucose transporters (GLUTs) (10), with GLUTs considered to be the most significant mechanism for enhancing glucose influx into cells. GLUTs are membrane proteins that facilitate the transport of glucose across cellular membranes. Thirteen members of the facilitative glucose transporter family are now recognized (GLUT-1 to -12 and HMIT; gene name SLC2A) (11). The human genes encoding these proteins are named GLUT-1 to -5 and GLUT-7 to -13 ; GLUT- 6 and -14 are now known to be pseudogenes. Of the 14 isoforms, GLUT-1 appears to be the most ubiquitously distributed $(10,12,13)$. Increased GLUT-1 levels and glucose uptake correlate with increased cellular growth and proliferation $(12,13)$. This isoform is overexpressed 
in many human cancer cells, and its appearance is correlated with aggressive biological behavior $(10,12)$. Thus, control of GLUT-1 trafficking and activity are also key elements in regulating glucose uptake. Similarly to the insulin-responsive glucose transporter GLUT-4, GLUT-1 cell-surface localization is controlled by extrinsic signals. Among the signaling pathways initiated in cell activation, the phosphatidylinositol 3-kinase $(\mathrm{PI} 3 \mathrm{~K}) /$ protein kinase B (Akt) pathway has been shown to promote both GLUT-1 cell-surface trafficking and activity $(14,15)$.

PI3K is a heterodimeric enzyme important for growth and proliferation and Akt is a downstream serine-threonine kinase that transmits survival signals from growth factors (15). The $\mathrm{PI} 3 \mathrm{~K} / \mathrm{Akt}$ pathway is frequently overactive in various tumors and triggers a cascade of responses, from cell growth and proliferation to cell survival and motility, which drives tumor progression (15-17). The PI3K/Akt pathway has been shown to be involved in translocating the GLUT-1 glucose transporter from the cytosol to the plasma membrane in endocrine organs such as the pancreas (15).

In the present study, we assessed the expression of GLUT-1, PI3K and p-Akt protein in ACCs using immunohistochemistry. Additionally, we examined the possible correlations between GLUT-1, PI3K and p-Akt protein expression and clinicopathological parameters in this cohort of patients.

\section{Patients and methods}

Patients. Forty-two patients with ACC from the Departments of Otolaryngology and Oral and Maxillofacial Surgery, the First Affiliated Hospital, College of Medicine, Zhejiang University, China were evaluated between January 1993 and February 2010. The institutional review board approved the present study, and written informed consent was obtained from the patients before inclusion. The clinicopathological findings (including age, gender, site, TNM stage, pathological type, recurrence, metastasis and follow-up) were analyzed (Table I).

Immunohistochemical analysis. For immunohistochemical evaluation, paraffin blocks of formalin-fixed biopsies were retrieved from pathology archives. In addition to tumor biopsies of the patients included in the current analysis, 15 paraffin-embedded archival tissue blocks from patients with nasal polyps, 15 from patients with vocal cord polyps, 5 from patients with nasal benign schwannomas and 20 tissue blocks from patients with nasal inverted papilloma were also obtained.

Sections were immunostained for GLUT-1, PI3K and p-Akt proteins using an EliVision ${ }^{\mathrm{TM}}$ plus IHC kit (Maixin Biological, Fuzhou, China), according to the standard protocol (17). The antibodies, dilutions, antigen-retrieval methods, sources and positive controls which were used are detailed in Table II. Antigen retrieval was performed after sections were deparaffinized with xylene and dehydrated through an ethanol series. Endogenous peroxidase activity was blocked by incubating slides in $1.5 \%$ hydrogen peroxide in absolute methanol at room temperature for $10 \mathrm{~min}$. Primary antibodies were applied for $1 \mathrm{~h}$ at room temperature, followed by $50 \mu \mathrm{l}$ polymer enhancer for $20 \mathrm{~min}$ and $50 \mu \mathrm{l}$ polymerized horseradish peroxidiseantimouse immunoglobulin $\mathrm{G}(\mathrm{IgG})$ for $30 \mathrm{~min}$. The reaction products were visualized using diaminobenzidine (DAB kit;
Table I. Clinicopathological findings of 42 adenoid cystic carcinomas.

\begin{tabular}{|c|c|c|c|c|}
\hline \multirow[b]{2}{*}{ Clinical characteristics } & \multirow[b]{2}{*}{$\mathrm{N}$} & \multicolumn{3}{|c|}{ Recurrence } \\
\hline & & $\mathrm{N}$ & $\chi^{2}$ & P-value \\
\hline \multicolumn{5}{|l|}{ Gender } \\
\hline Female & 29 & 11 & 0.25 & $>0.05$ \\
\hline Male & 13 & 6 & & \\
\hline \multicolumn{5}{|l|}{ Age (years) } \\
\hline$<60$ & 15 & 9 & 3.69 & $>0.05$ \\
\hline$\geq 60$ & 27 & 8 & & \\
\hline \multicolumn{5}{|l|}{ Site } \\
\hline Major salivary gland & 16 & 6 & 0.21 & $>0.05$ \\
\hline Minor salivary gland & 22 & 9 & & \\
\hline Other & 4 & 2 & & \\
\hline \multicolumn{5}{|l|}{ Pathological type } \\
\hline Cribriform & 28 & 11 & 0.79 & 0.67 \\
\hline Tubular & 4 & 1 & & \\
\hline Solid & 10 & 5 & & \\
\hline \multicolumn{5}{|l|}{ T stage } \\
\hline $\mathrm{T}_{1}$ & 14 & 3 & 10.5 & 0.015 \\
\hline $\mathrm{T}_{2}$ & 15 & 4 & & \\
\hline $\mathrm{T}_{3}$ & 9 & 7 & & \\
\hline $\mathrm{T}_{4}$ & 4 & 2 & & \\
\hline \multicolumn{5}{|l|}{ Lymph node metastasis } \\
\hline Yes & 22 & 10 & 0.48 & $>0.05$ \\
\hline No & 20 & 7 & & \\
\hline \multicolumn{5}{|l|}{ Resection margin positive } \\
\hline Yes & 9 & 8 & & 0.001 \\
\hline No & 33 & 9 & & $\begin{array}{l}\text { Fisher's } \\
\text { ixact Test }\end{array}$ \\
\hline \multicolumn{5}{|l|}{ Perineural invasion } \\
\hline Yes & 19 & 13 & 11.2 & 0.001 \\
\hline No & 23 & 4 & & \\
\hline \multicolumn{5}{|l|}{ Treatment } \\
\hline Surgery & 30 & 15 & 3.9 & 0.047 \\
\hline Surgery + radiotherapy & 12 & 2 & & \\
\hline
\end{tabular}

Maixin Biological) and sections were counterstained with hematoxylin and eosin ( $\mathrm{H} \& \mathrm{E})$, dehydrated and evaluated by light microscopy. Tris-buffered saline solution was used instead of the primary antibody for negative controls. Erythrocytes, which were present in every section, served as internal controls for GLUT-1 to ensure constant immunostaining intensity.

Evaluation of stained sections. GLUT-1, PI3K and p-Akt immunostaining was evaluated by the same investigator (H.T.Y.), who was blinded to the clinical and follow-up data. GLUT-1 expression was considered positive only if distinct membrane staining was present. PI3K and p-Akt proteins were observed in the nucleus and cytoplasm. Protein analysis was performed in 10 random high-power fields. A total of 100 tumor cells were counted from each high-power field for 
Table II. Antibodies used in the immunohistochemical analysis.

\begin{tabular}{lllll}
\hline Antibody & Dilution & \multicolumn{1}{c}{ Manufacturer } & Antigen retrieval method & Positive control \\
\hline GLUT-1 & $1: 50$ & Dako, Carpinteria, CA, USA & Enzyme & Erythrocytes \\
PI3K & $1: 100$ & Santa Cruz Biotechnology Inc., Santa Cruz, CA, USA & Microwave & Breast carcinoma \\
p-Akt & $1: 50$ & Santa Cruz Biotechnology Inc., Santa Cruz, CA, USA & Microwave & Glioblastoma multiforme \\
\hline
\end{tabular}

GLUT-1, glucose transporter 1; PI3K, phosphatidylinositol 3-kinase; p-Akt, phosphorylated protein kinase B.

Table III. Immunohistochemical results of GLUT-1, PI3K and p-Akt in adenoid cystic carcinomas, inflammatory lesions and benign tumors.

\begin{tabular}{|c|c|c|c|c|c|c|c|c|c|c|}
\hline \multirow[b]{2}{*}{ Group } & \multirow[b]{2}{*}{$\mathrm{N}$} & \multicolumn{2}{|c|}{ GLUT-1 } & \multirow[b]{2}{*}{ P-value } & \multicolumn{2}{|c|}{ PI3K } & \multirow[b]{2}{*}{ P-value } & \multicolumn{2}{|c|}{$\mathrm{p}$-Akt } & \multirow[b]{2}{*}{ P-value } \\
\hline & & + & - & & + & - & & + & - & \\
\hline Inflammatory lesions & 30 & 0 & 30 & $<0.001$ & 0 & 30 & $<0.001$ & 0 & 30 & $<0.001$ \\
\hline Benign tumors & 25 & 0 & 25 & $<0.001$ & 1 & 24 & $<0.001$ & 3 & 22 & $<0.001$ \\
\hline $\mathrm{ACC}$ & 42 & 16 & 26 & $<0.001$ & 16 & 26 & 0.001 & 21 & 21 & $<0.001$ \\
\hline
\end{tabular}

There was a significant difference among the 3 groups of adenoid cystic carcinomas, inflammatory lesions and benign tumors. When compared with inflammatory lesions and benign tumors, the expression of GLUT-1, PI3K and p-Akt in ACC was higher (Fisher's exact test). GLUT-1, glucose transporter 1; PI3K, phosphatidylinositol 3-kinase; p-Akt, phosphorylated protein kinase B.

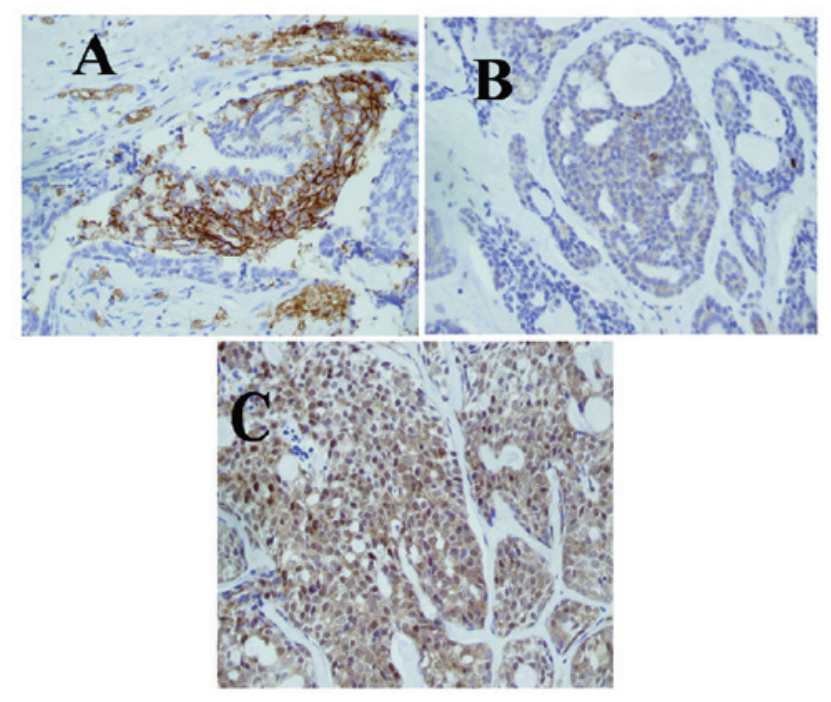

Figure 1. Immunohistochemical staining was positive for (A) GLUT-1, (B) PI3K and (C) p-Akt in adenoid cystic carcinomas (magnification, $\mathrm{x} 40$ ). GLUT-1, glucose transporter 1; PI3K, phosphatidylinositol 3-kinase; p-Akt, phosphorylated protein kinase B.

each case and for all antibodies analyzed. The percentage of positive cells was calculated by dividing the number of positive tumor cells by the total number of tumor cells counted. Staining was considered to be negative when $<25 \%$ of the cells were positive.

Statistical analysis. Analyses were performed using the SPSS for Windows software (version 19.0; SPSS Inc., Chicago, IL, USA). Correlations among GLUT-1, PI3K and p-Akt protein expression and the other pretreatment parameters were analyzed using the Chi-square test and Fisher's exact test. The logistic regression test was used for the multivariate analysis. $\mathrm{P}<0.05$ was considered to indicate a statistically significant result. The correlation analysis was performed using Spearman's Rho.

\section{Results}

Patient characteristics. Of the 42 ACC tumor tissues, 9 (21.5\%) were located in the submandibular gland, $6(14.3 \%)$ in the parotid gland, $5(11.9 \%)$ in the palate, $4(9.5 \%)$ in the paranasal sinus, $4(9.5 \%)$ in the external auditory canal, $3(7.1 \%)$ in the nasal cavity, $3(7.1 \%)$ in the larynx, $3(7.1 \%)$ in the floor of the mouth, one $(2.4 \%)$ in the sublingual gland, one $(2.4 \%)$ in the tongue, one $(2.4 \%)$ in the pterygomandibular space, one $(2.4 \%)$ in the buccal mucosa and one $(2.4 \%)$ in the trachea (Table I). Among these, $16(38.1 \%)$ were located in the major salivary gland, $22(52.4 \%)$ were in the minor salivary gland and $4(9.5 \%)$ were in the external auditory canal. The median age of the 42 patients was 52.4 years (range, 32-83 years). Thirteen patients were male and 29 were female. Surgery was performed in all patients. Twenty-two patients had enlarged ipsilateral lymph nodes $\left(\mathrm{N}_{1}\right)$ and received neck dissection. Thirty patients did not receive postoperative radiotherapy following initial surgery (Table I).

Tumor-node-metastasis (TNM) classification and stage were assigned based on the sixth edition of the American Joint Committee on Cancer (AJCC) staging manual. Fourteen of the patients $(33.3 \%)$ had cancer classified as $\mathrm{T}_{1}$ stage, $15(35.7 \%)$ had $\mathrm{T}_{2}$ stage, $9(21.4 \%)$ had $\mathrm{T}_{3}$ stage and $4(9.6 \%)$ had $\mathrm{T}_{4 \mathrm{a}}$ stage cancer. 
Table IV. Correlation between the clinicopathological features and expression of GLUT-1, PI3K and p-Akt.

\begin{tabular}{|c|c|c|c|c|c|c|c|c|c|c|}
\hline \multirow{2}{*}{$\begin{array}{l}\text { Clinicopathological } \\
\text { features }\end{array}$} & \multicolumn{3}{|c|}{ GLUT-1 } & \multicolumn{3}{|c|}{$\mathrm{p}-\mathrm{Akt}$} & \multicolumn{3}{|c|}{ PI3K } & \multirow[b]{2}{*}{ P-value } \\
\hline & $\mathrm{N}$ & + & $\chi^{2}$ & P-value & + & $\chi^{2}$ & P-value & + & $\chi^{2}$ & \\
\hline \multicolumn{11}{|l|}{ Gender } \\
\hline Female & 29 & 11 & 0.12 & $>0.05$ & 15 & 0.20 & $>0.05$ & 10 & 0.52 & $>0.05$ \\
\hline Male & 13 & 5 & & & 6 & & & 6 & & \\
\hline \multicolumn{11}{|l|}{ Age (years) } \\
\hline$<60$ & 27 & 9 & 0.73 & $>0.05$ & 14 & 0.10 & $>0.05$ & 11 & 0.22 & $>0.05$ \\
\hline$\geq 60$ & 15 & 7 & & & 7 & & & 5 & & \\
\hline \multicolumn{11}{|l|}{ Histopathological type } \\
\hline Cribriform & 28 & 11 & 0.54 & $>0.05$ & 12 & 2.17 & $>0.05$ & 10 & 0.32 & $>0.05$ \\
\hline Tubular & 4 & 2 & & & 2 & & & 2 & & \\
\hline Solid & 10 & 3 & & & 7 & & & 4 & & \\
\hline \multicolumn{11}{|l|}{ T stage } \\
\hline $\mathrm{T}_{1}$ & 14 & 1 & 14.15 & 0.003 & 4 & 4.64 & $>0.05$ & 4 & 4.84 & $>0.05$ \\
\hline $\mathrm{T}_{2}$ & 15 & 5 & & & 8 & & & 4 & & \\
\hline $\mathrm{T}_{3}$ & 9 & 7 & & & 6 & & & 5 & & \\
\hline $\mathrm{T}_{4}$ & 4 & 3 & & & 3 & & & 3 & & \\
\hline \multicolumn{11}{|l|}{ Lymph node metastasis } \\
\hline Yes & 22 & 11 & 2.77 & $>0.05$ & 10 & 0.38 & $>0.05$ & 10 & 1.06 & $>0.05$ \\
\hline No & 20 & 5 & & & 11 & & & 6 & & \\
\hline \multicolumn{11}{|l|}{ Site } \\
\hline Major salivary gland & 16 & 6 & 0.27 & $>0.05$ & 8 & 1.18 & & 7 & & \\
\hline Minor salivary gland & 22 & 8 & & & 10 & & & 9 & & \\
\hline Other & 4 & 2 & & & 3 & & $>0.05$ & 0 & 2.75 & $>0.05$ \\
\hline \multicolumn{11}{|l|}{ Metastasis } \\
\hline Yes & 4 & 4 & Fisher's & 0.016 & 3 & Fisher's & 0.61 & 2 & 0.27 & $>0.05$ \\
\hline No & 38 & 12 & Exact test & & 18 & Exact Test & & 14 & & \\
\hline \multicolumn{11}{|l|}{ Recurrence } \\
\hline Yes & 17 & 12 & Fisher's & 0.001 & 15 & 16.7 & $<0.001$ & 11 & 8.58 & 0.003 \\
\hline No & 25 & 4 & Exact test & & 6 & & & 5 & & \\
\hline
\end{tabular}

GLUT-1, glucose transporter 1; PI3K, phosphatidylinositol 3-kinase; p-Akt, phosphorylated protein kinase B.

The patients' average follow-up period was 51.9 months (range, 6-293 months). Four patients were lost to follow-up. Four patients $(9.5 \%)$ developed distant metastases and $2(4.8 \%)$ succumbed to distant metastases. Thirty-three patients were alive at the last follow-up. The median overall survival (OS) was 187 months [95\% confidence interval (CI), 118-257]. The 5- and 10-year OS probabilities were 79\% (95\% CI, 61.9-83.2\%) and 53\% (95\% CI, 41.1-66.7\%), respectively. There was no significant clinical factor identified as a prognostic predictor $(\mathrm{P}>0.05)$. Of the 42 patients with follow-up, $17(40.5 \%)$ developed recurrence following initial surgery, with a median follow-up period of 30.3 months (range, 5-70 months). Univariate analyses showed that $\mathrm{T}$ stage, a positive resection margin, perineural invasion and surgery without postoperative radiotherapy were significantly associated with a higher recurrence risk $\left(\chi^{2}=10.5, \mathrm{P}=0.015 ; \mathrm{P}=0.001\right.$, Fisher's exact test; $\chi^{2}=11.2, \mathrm{P}=0.001 ; \chi^{2}=3.9, \mathrm{P}=0.047$, respectively). Site, tumor stage, pathological type and gender did not influence the risk of recurrence in the present study (Table I).
Patients who had local recurrence received radical surgery and those who did not received radiotherapy following surgery, or salvage surgical treatment plus chemotherapy.

GLUT-1, PI3K and Akt protein expression in ACC. The positive rates of GLUT-1, PI3K and p-Akt protein in ACC were $38.1 \%$ (16/42), 38.1\% (16/42) and 50.0\% (21/42), respectively (Table III, Fig. 1). The expression of GLUT-1, p-Akt and PI3K protein in ACC was higher than that in inflammatory lesions or benign tumors ( $\mathrm{p}<0.001$; Table III).

Correlation among GLUT-1, PI3K and p-Akt protein expression and PI3K/p-Akt combinatorial groups. The Spearman's Rho analysis showed significant correlations between GLUT-1 and PI3K expression $(\mathrm{r}=0.394, \mathrm{P}=0.01)$, GLUT-1 and $\mathrm{p}-\mathrm{Akt}$ expression $(\mathrm{r}=0.528, \mathrm{P}<0.001)$ and $\mathrm{p}-\mathrm{Akt}$ and $\mathrm{PI} 3 \mathrm{~K}$ expression $(r=0.528, \mathrm{P}<0.001)$. According to the expression of $\mathrm{p}-\mathrm{Akt}$ and $\mathrm{PI} 3 \mathrm{~K}$, the prevalence of the four phenotypic groups was $31.0 \%$ p-Akt ${ }^{+} / \mathrm{PI} 3 \mathrm{~K}^{+}, 21.4 \%$ p-Akt $/ \mathrm{PI} 3 \mathrm{~K}^{-}, 7.1 \% \mathrm{p}-\mathrm{Akt} / \mathrm{PI} 3 \mathrm{~K}^{+}$ 
and $40.5 \% \mathrm{p}-\mathrm{Akt} / \mathrm{PI} 3 \mathrm{~K}$. A significant positive correlation was noted between the phenotypic groups, $\mathrm{T}$ stage $(\mathrm{p}=0.022)$ and recurrence $(\mathrm{P}=0.000)$.

Association of GLUT-1, PI3K and p-Akt with clinicopathological parameters. The correlation between GLUT-1, PI3K and p-Akt expression and clinicopathological features is shown in Table III. Univariate analyses revealed that there was a significant correlation between GLUT-1 expression, T stage $(\mathrm{P}=0.003)$, distant metastasis $(\mathrm{P}=0.016)$ and local recurrence $(\mathrm{P}=0.001$; Table IV). The expression of GLUT-1 was not significantly correlated with other clinicopathological factors (gender, age, pathological type, lymph node metastasis, site and survival). A significant positive correlation was noted between PI3K expression $(\mathrm{P}<0.001)$, p-Akt expression $(\mathrm{P}=0.003)$ and local recurrence. The expression of PI3K and p-Akt was not significantly correlated with other clinicopathological factors (gender, age, pathological type, TNM stage, site and survival), therefore these markers were not predictors of OS.

In multivariate analyses, perineural invasion $(\mathrm{P}=0.021)$, a positive resection margin $(\mathrm{P}=0.032)$ and $\mathrm{p}-\mathrm{Akt}(\mathrm{P}=0.006)$ were significant predictors of recurrence.

\section{Discussion}

In agreement with previous studies $(1,7,8,10)$, we found that ACC in our patients had a high recurrence rate, similar to that observed in the study of Chen et al (18). The recurrence rate was up to $40.5 \%$, and mostly occurred within 5 years of initial treatment. The mean time to recurrence was 40 months (range, 9-70 months). The patients' average follow-up period was 51.9 months (range, 6-293 months). Four patients were lost to follow-up. Four patients (9.5\%) developed distant metastases and 2 succumbed to distant metastases. Thirty-three patients were alive at the last follow-up. The median OS was 187 months. There were no significant factors, such as the expression of GLUT-1, p-Akt and PI3K, identified as prognostic predictors $(\mathrm{P}>0.05)$.

The analysis of clinicopathological factors influencing recurrence revealed that $\mathrm{T}$ stage, a positive resection margin, perineural invasion and surgery without postoperative radiotherapy were predictive of recurrence by univariate analyses. However, only perineural invasion $(\mathrm{P}=0.021)$ and a positive resection margin showed a higher risk of recurrence of $\mathrm{ACC}$ of the head and neck by multivariate analysis. Most authors have suggested that routine postoperative radiotherapy is a factor for the local control of ACC of the head and neck (18-21). Chen et al suggested that postoperative radiotherapy was an effective factor in controlling the local recurrence of ACC in the head and neck (18). The 5- and 10-year rates of local control were 92 and $84 \%$, respectively, for patients treated with postoperative radiation compared with 80 and $61 \%$, respectively, for those treated with surgery alone. They also found that stage $\mathrm{T}_{4}$ disease, positive surgical margins, perineural invasion and major (named) nerve involvement were factors predicting local recurrence (18). Mendenhall et al reported higher local control rates of ACC of the head and neck for surgery combined with postoperative radiotherapy than most other studies (21). The 5- and 10-year rates of local control were 94 and $91 \%$, respectively, for patients treated with postoperative radiation compared with 56 and 43\%, respectively, for those treated with surgery alone. If radiation therapy is administered to patients, the dose should be no less than 60 Gy (21). Mendenhall et al also found that T stage influenced local control (21). Prokopakis et al reported that the tumor site was the single most important factor predicting the development of locally recurrent disease and was correlated with primary tumor stage and resection margins (20). However, Iseli et al proposed that no significant correlation was evident between improved local control in patients with ACC of the head and neck receiving surgery plus postoperative radiotherapy compared with patients receiving surgery alone (22).

In the present study, we analyzed additional recurrence factors of ACC of the head and neck at the molecular biomarker level by assessing glucose metabolism by immunohistochemistry. We found that the GLUT-1 expression rate was $38.1 \%$, the p-Akt expression rate was $50.0 \%$ and the PI3K expression rate was $38.1 \%$. The expression of these markers was higher in ACC than in inflammatory tissues and tissues of benign tumors $(\mathrm{P}<0.001)$. Our results indicate that GLUT-1, PI3K and $\mathrm{p}$-Akt may be useful in predicting recurrence in patients with ACC of the head and neck. In multivariate analyses, only p-Akt was a significant predictor of recurrence. We also found that GLUT-1 was associated with T stage and distant metastasis of ACC. This result was similar to our previous study as well as to other studies (23-26). We found that GLUT-1 expression was higher in head and neck carcinoma than in normal tissues and adjacent carcinoma tissues (23). As early as 1996, Younes et al demonstrated that GLUT-1 expression was higher in various malignant tumors than in benign counterparts using immunohistochemistry and suggested that GLUT-1 played a crucial role in carcinogenesis (24). Pizzi et al confirmed that GLUT-1 was involved in a relatively early phase of pancreatic carcinogenesis (25). Semaan et al showed that GLUT-1 expression was correlated with tumor proliferation and microvessel density in epithelial ovarian carcinoma (26). In ACC, Campistron et al reported a high uptake of ${ }^{18} \mathrm{~F}-\mathrm{FDG}$ by the lung and a case of liver metastasis in a patient with lung ACC by PET/CT. The liver ${ }^{18} \mathrm{~F}-\mathrm{FDG}$ uptake was confirmed by GLUT-1-positive immunostaining (9). These findings showed that GLUT-1 expression was correlated with the transformation of benign tissue from borderline to invasive cancer. Völker et al (27) found that the expression of p-Akt was an independent predictor of higher relapse risk in ACC, as was incomplete surgical resection (27); however, GLUT-1 was not associated with recurrence and metastasis. Thus, the significance of GLUT-1 expression in ACC of the head and neck should be further studied.

GLUT-1 expression reflects the hypoxia of malignant tumors $(12,23,26)$ and may be activated by the PI3K/Akt pathway. The PI3K/Akt pathway has been shown to promote both GLUT-1 cell-surface trafficking and activity $(14,15)$. The activation and phosphorylation of PI3K/Akt are not only well-recognized regulators of cell growth, survival and angiogenesis, but they also play an important role in promoting glucose metabolism (28). The activation of Akt may be responsible for the metabolic processes occurring during the Warburg effect (29). Melstrom et al found that PI3K inhibitors downregulated both GLUT-1 mRNA and protein expression and suggested that the PI3K/Akt pathway 
is involved in mediating GLUT-1 (15). In the present study, the correlations between GLUT-1 and PI3K expression, between GLUT-1 and p-Akt expression and between p-Akt and PI3K expression were significant. For further scrutiny of the effect of the PI3K/Akt pathway in mediating GLUT-1 expression, tumors were redefined according to their combined GLUT-1 and p-Akt immunohistochemical status, resulting in 4 phenotypes: $\mathrm{p}-\mathrm{Akt}^{+} / \mathrm{GLUT}^{+}, \mathrm{p}-\mathrm{Akt}^{+} / \mathrm{GLUT}^{-}, \mathrm{p}-\mathrm{Akt}^{-} / \mathrm{GLUT}^{+}$and $\mathrm{p}-\mathrm{Akt}^{-} / \mathrm{GLUT}^{-}$. We observed that the prevalence of the 4 phenotypic groups was $31.0 \% \mathrm{p}-\mathrm{Akt}^{+} / \mathrm{GLUT}^{+}, 16.7 \% \mathrm{p}-\mathrm{Akt}^{+} / \mathrm{GLUT}^{-}$, 9.4\% $\mathrm{p}-\mathrm{Akt}^{-} / \mathrm{GLUT}^{+}$and $42.9 \% \mathrm{p}-\mathrm{Akt}^{-} / \mathrm{GLUT}^{-}$. The consistency of GLUT-1 expression and p-Akt expression was $59.6 \%$, suggesting that p-Akt may regulate GLUT-1 expression. One mechanism may be that Akt stimulates GLUT-1 transcription via the phosphorylation of a particular protein(s) (30). However, another possible mechanism may be that Akt does not affect the expression of the GLUT-1 gene, but Akt-driven glucose uptake and phosphorylation by GLUT-1 causes an accumulation of glucose-6-phosphate, which acts to provide cell survival signals, and Akt maintains cell-surface GLUT-1 localization (31). However, an inconsistency of expression between GLUT-1 and p-Akt existed (p-Akt ${ }^{+} / \mathrm{GLUT}^{-}$and $\mathrm{p}-\mathrm{Akt}^{-} / \mathrm{GLUT}^{+}$). This suggested that other signaling pathways may play a role in regulating the expression of GLUT-1, such as MAPK pathways (32). Thus, the mechanism by which the PI3K/Akt signaling pathway affects GLUT-1 expression remains unclear.

In ACC, few studies exist regarding the expression of signaling proteins of the PI3K/Akt pathway $(27,33)$. These studies have only analyzed the expression of p-Akt $(27,33)$. Although our study may be limited by the small number of patients, to our knowledge, this study is the first to detect the two signaling proteins, p-Akt and PI3K, in ACC. In our cohort, the prevalence of the 4 phenotypic groups was $31.0 \%$ $\mathrm{p}-\mathrm{Akt}^{+} / \mathrm{PI} 3 \mathrm{~K}^{+}, 21.4 \% \mathrm{p}-\mathrm{Akt}^{+} / \mathrm{PI} 3 \mathrm{~K}^{-}, 7.1 \% \mathrm{p}-\mathrm{Akt}^{-} / \mathrm{PI}^{+} \mathrm{K}^{+}$and $40.5 \% \mathrm{p}-\mathrm{Akt} / \mathrm{PI} 3 \mathrm{~K}^{-}$. A significant positive correlation was found between these phenotypic groups, $T$ stage $(p=0.022)$ and recurrence $(\mathrm{p}=0.000)$. The $\mathrm{PI} 3 \mathrm{~K}^{+}$groups $\left(\mathrm{p}-\mathrm{Akt} / \mathrm{PI} 3 \mathrm{~K}^{+}\right.$ and $\mathrm{p}-\mathrm{Akt}^{+} / \mathrm{PI} 3 \mathrm{~K}^{+}$) showed higher recurrence rates than the $\mathrm{PI}^{-} \mathrm{K}^{-}$groups $\left(\mathrm{p}-\mathrm{Akt}^{+} / \mathrm{PI} 3 \mathrm{~K}^{-}\right.$and $\left.\mathrm{p}-\mathrm{Akt}^{-} / \mathrm{PI} 3 \mathrm{~K}^{-}\right)$. Aleskandarany et al demonstrated that the prevalence of overexpressed $\mathrm{p}-\mathrm{Akt}$ was $76 \%$ and that of PI3K was $75 \%$ in breast cancer (33). This relatively high prevalence of p-Akt may be a reflection of the oncogenetic role that was reported to occur early during the cascade of carcinogenic events, as observed in in situ stage carcinomas prior to their progression to invasive carcinomas (33). They also found that significant differences among these combinatorial phenotypic groups were noted for breast cancer-specific survival and metastasis-free survival. In our study, the proportion of $\mathrm{p}-\mathrm{Akt}^{+} / \mathrm{PI} 3 \mathrm{~K}^{-}$was $21.4 \%$ and $\mathrm{p}-\mathrm{Akt} / \mathrm{PI} 3 \mathrm{~K}^{+}$was $7.1 \%$. These results show that the expression of PI3K and Akt was incoordinate and suggest that the activation of Akt in ACC may occur through mechanisms of Akt activation rather than through PI3K (34).

In summary, our study has demonstrated that $\mathrm{T}$ stage, a positive resection margin, perineural invasion, surgery without postoperative radiotherapy and expression of GLUT-1, $\mathrm{PI} 3 \mathrm{~K}$ and p-Akt were factors predictive of ACC recurrence by univariate analyses. In multivariate analyses, perineural invasion, a positive resection margin and p-Akt were significant predictors of recurrence. Thus, initial surgery is very important for the recurrence of ACC of the head and neck. The expression of GLUT-1, p-Akt or PI3K protein in ACC was higher than that in inflammatory lesions or benign tumors; therefore, overexpression of these biomarkers may play a role in the development of ACC.

\section{Acknowledgements}

This study was supported by grants from the Department of Health Bureau, Zhejiang, China (No. 2009B042), the Science and Technology Department of Zhejiang Province (No. 2009C33026), and the National Natural Science Foundation of China (No. 81172562).

\section{References}

1. Zvrko E and Golubović M: Laryngeal adenoid cystic carcinoma. Acta Otorhinolaryngol Ital 29: 279-282, 2009.

2. Lupinetti AD, Roberts DB, Williams MD, et al: Sinonasal adenoid cystic carcinoma: the M.D. Anderson Cancer Center experience. Cancer 110: 2726-2731, 2007

3. Cruz Perez DE, Pires FR, Lopes MA, de Almeida OP and Kowalski LP: Adenoid cystic carcinoma and mucoepidermoid carcinoma of the maxillary sinus: report of a 44-year experience of 25 cases from a single institution. J Oral Maxillofac Surg 64: 1592-1597, 2006

4. Dong F, Gidley PW, Ho T, et al: Adenoid cystic carcinoma of the external auditory canal. Laryngoscope 118: 1591-1596, 2008.

5. van der Wal JE, Becking AG, Snow GB and van der Waal I: Distant metastases of adenoid cystic carcinoma of the salivary glands and the value of diagnostic examinations during follow-up. Head Neck 24: 779-783, 2002.

6. Gomez DR, Hoppe BS, Wolden SL, et al: Outcomes and prognostic variables in adenoid cystic carcinoma of the head and neck: a recent experience. Int J Radiat Oncol Biol Phys 70: 1365-1372, 2008.

7. Ko YH, Lee MA, Hong YS, et al: Prognostic factors affecting the clinical outcome of adenoid cystic carcinoma of the head and neck. Jpn J Clin Oncol 37: 805-811, 2007.

8. Shang J, Sheng L, Wang K, Shui Y and Wei Q: Expression of neural cell adhesion molecule in salivary adenoid cystic carcinoma and its correlation with perineural invasion. Oncol Rep 18: 1413-1416, 2007.

9. Campistron M, Rouquette I, Courbon F, et al: Adenoid cystic carcinoma of the lung: interest of $18 \mathrm{FDG}$ PET/CT in the management of an atypical presentation. Lung Cancer 59: 133-136, 2008.

10. Li LF, Zhou SH, Zhao K, et al: Clinical significance of FDG single-photon emission computed tomography: computed tomography in the diagnosis of head and neck cancers and study of its mechanism. Cancer Biother Radiopharm 23: 701-714, 2008.

11. Wood IS and Trayhurn P: Glucose transporters (GLUT and SGLT): expanded families of sugar transport proteins. Br J Nutr 89: 3-9, 2003.

12. Chung JK, Lee YJ, Kim SK, Jeong JM, Lee DS and Lee MC: Comparison of [18F] fluorodeoxyglucose uptake with glucose transporter-1 expression and proliferation rate in human glioma and non-small-cell lung cancer. Nucl Med Commun 25: 11-17, 2004.

13. Zhou SH, Fan J, Chen XM, Cheng KJ and Wang SQ: Inhibition of cell proliferation and glucose uptake in human laryngeal carcinoma cells by antisense oligonucleotides against glucose transporter-1. Head Neck 31: 1624-1633, 2009.

14. Jacobs SR, Herman CE, Maciver NJ, et al: Glucose uptake is limiting in $\mathrm{T}$ cell activation and requires CD28-mediated Akt-dependent and independent pathways. J Immunol 180: 4476-4486, 2008.

15. Melstrom LG, Salabat MR, Ding XZ, et al: Apigenin inhibits the GLUT-1 glucose transporter and the phosphoinositide 3-kinase/Akt pathway in human pancreatic cancer cells. Pancreas 37: 426-431, 2008.

16. Bussink J, van der Kogel AJ and Kaanders JH: Activation of the PI3-K/AKT pathway and implications for radioresistance mechanisms in head and neck cancer. Lancet Oncol 9: 288-296, 2008. 
17. Fang J, Luo XM, Yao HT, Zhou SH, Ruan LX and Yan SX: Expression of glucose transporter-1, hypoxia-inducible factor-1 $\alpha$, phosphatidylinositol 3-kinase and protein kinase B (Akt) in relation to $[(18) \mathrm{F}]$ fluorodeoxyglucose uptake in nasopharyngeal diffuse large B-cell lymphoma: a case report and literature review. J Int Med Res 38: 2160-2168, 2010.

18. Chen AM, Bucci MK, Weinberg V, et al: Adenoid cystic carcinoma of the head and neck treated by surgery with or without postoperative radiation therapy: prognostic features of recurrence. Int J Radiat Oncol Biol Phys 66: 152-159, 2006.

19. Ko YH, Roh SY, Won HS, et al: Prognostic significance of nuclear survivin expression in resected adenoid cystic carcinoma of the head and neck. Head Neck Oncol 2: 30, 2010.

20. Prokopakis EP, Snyderman CH, Hanna EY, Carrau RL, Johnson JT and D'Amico F: Risk factors for local recurrence of adenoid cystic carcinoma: the role of post-operative radiotherapy. Am J Otolarygo 120: 281-286, 1999.

21. Mendenhall WM, Morris CG, Amdur RJ, Werning JW, Hinerman RW and Villaret DB: Radiotherapy alone or combined with surgery for adenoid cystic carcinoma of the head and neck. Head Neck 26: 154-162, 2004.

22. Iseli TA, Karnell LH, Graham SM, et al: Role of radiotherapy in adenoid cystic carcinoma of the head and neck. J Laryngol Otol 123: 1137-1144, 2009.

23. Zhou S, Wang S, Wu Q and Wang Q: Expression of glucose transporter-1 and -3 in the head and neck carcinoma - The correlation of the expression with the biological behaviors. ORL J Otorhinolaryngol Relat Spec 70: 189-194, 2008.

24. Younes M, Lechago LV, Somoano JR, Mosharaf M and Lechago J: Wide expression of the human erythrocyte glucose transporter Glut1 in human cancers. Cancer Res 56: 1164-1167, 1996.

25. Pizzi S, Porzionato A, Pasquali C, et al: Glucose transporter-1 expression and prognostic significance in pancreatic carcinogenesis. Histol Histopathol 24: 175-185, 2009.
26. Semaan A, Munkarah AR, Arabi H, et al: Expression of GLUT-1 in epithelial ovarian carcinoma: Correlation with tumor cell proliferation, angiogenesis, survival and ability to predict optimal cytoreduction. Gynecol Oncol 121: 181-186, 2011.

27. Völker HU, Scheich M, Berndt A, et al: Expression of p-AKT characterizes adenoid cystic carcinomas of head and neck with a higher risk for tumor relapses. Diagn Patho 19: 18, 2009.

28. Paik JY, Ko BH, Jung KH and Lee KH: Fibronectin stimulates endothelial cell 18F-FDG uptake through focal adhesion kinasemediated phosphatidylinositol 3-kinase/Akt signaling. J Nucl Med 50: 618-624, 2009.

29. Elstrom RL, Bauer DE, Buzzai M, et al: Akt stimulates aerobic glycolysis in cancer cells. Cancer Res 64: 3892-3899, 2004.

30. Barthel A, Okino ST, Liao J, et al: Regulation of GLUT1 gene transcription by the serine/threonine kinase Akt1. J Biol Chem 274: 20281-20286, 1999.

31. Rathmell JC, Fox CJ, Plas DR, Hammerman PS, Cinalli RM and Thompson CB: Akt-directed glucose metabolism can prevent Bax conformation change and promote growth factorindependent survival. Mol Cell Biol 23: 7315-7328, 2003.

32. Lee YK, Kim JE, Nam SH, et al: Differential regulation of the biosynthesis of glucose transporters by the PI3-K and MAPK pathways of insulin signaling by treatment with novel compounds from Liriope platyphylla. Int J Mol Med 27: 319-327, 2011.

33. Aleskandarany MA, Rakha EA, Ahmed MA, Powe DG, Ellis IO and Green AR: Clinicopathologic and molecular significance of phospho-Akt expression in early invasive breast cancer. Breast Cancer Res Treat 127: 407-416, 2011.

34. Carpten JD, Faber AL, Horn C, et al: A transforming mutation in the pleckstrin homology domain of AKT1 in cancer. Nature 448: 439-444, 2007. 